\title{
Postnatal Changes in the Structure of Rat Testis
}

\section{Hegazy AA, Ahmad MM, Aziz JA and Abd Almotaleb NA* \\ Department of Human Anatomy and Embryology, Zagazig University, Egypt}

*Corresponding author: Noha Ali Abd Almotaleb, Department of Human Anatomy and Embryology, Faculty of Medicine, Zagazig University, Egypt, Tel: 00201065556726;

Email: Nannoo_25@yahoo.com

\section{Research Article \\ Volume 3 Issue 2}

Received Date: August 05, 2019

Published Date: August 19, 2019

DOI: $10.23880 /$ jes- 16000123

\section{Abstract}

Background: Postnatal development of rats' testes passes through stages. Elucidation of changes occurring at each age stage is essential to recognize any pathological deviation.

Aim: It was to investigate the histological and ultrastructure features of the rats' testes at different postnatal stages.

Methods: Eight healthy non-pregnant adult female albino rats weighting 150-250 gm were brought to be pregnant. Their male pups were divided into four groups (10 each), according their postnatal day (PND) at the time of scarification as follows: group I, II, III and IV at 1st, 21st, 35th and 70th PND respectively. The testes were dissected and processed for both light microscope (LM) and electron microscope (EM) investigations.

Results: Neonatal rat testis (group I) was formed of seminiferous cords containing gonocytes and immature Sertoli cells. The gonocytes or fetal germ cells were the most prominent finding in 1st PND within the non-canalized seminiferous cords. At PND 21 (group II), tubular diameter was increased with appearance of rounded spermatid at PND 26. The cell layers of the lining epithelium of the tubules were formed of spermatogonia, Sertoli cells and primary spermatocytes with large rounded cells with clumped chromatin. At PND 35 (group III), the tubular diameter was increased and showed more stratification of their epithelial lining with increased tubular cell layers. At PND 70 (group IV), the testis was formed of large seminiferous tubules, closely packed together.

Conclusion: Development of testis is a continuous process in postnatal life reaching its maximum at sexual maturity "about 2 months of rat birth".

Keywords: Testis; Anatomy; Development; Ultrastructure

\section{Introduction}

The testis is the primary sex organs in males; its function is not only the production of male gametes but also synthesis and controlled release of the main androgen (testosterone) [1]. Testosterone plays many roles which include differentiation of spermatocytes, development of normal sperm, proliferation and function of Leydig cells, myoid cells and the Sertoli cells [2].
The embryological sources of the developing testes are 1- coelomic epithelium that outlines the urogenital ridges, 2- intermediate mesoderm that forms the urogenital ridges on the posterior abdominal wall and 3- primordial germ cells that move from the yolk sac into the developing gonads across the dorsal mesentery [3]. The testis differentiation becomes evident in the sixth week of gestation. The primitive sex cords enlarge and become well defined; and their cells represent the precursors of the Sertoli cells. The outer portions of the testicular sex 


\section{Journal of Embryology \& Stem Cell Research}

cords form the seminiferous tubules, and the inner portions form the rete testis. The rete testis joins the efferent ductules which develop from mesonephric tubules [4].

Precursors of the Sertoli cells should be prepared to receive the genetic signals for testicular differentiation by a certain time. If this does not happened, the primordial germ cells (PGCs) begin to undergo meiosis, and the gonad differentiates into an ovary [5]. The number of Sertoli cells in the testis is the primary factor in determining the number of sperm production per day. At the same time, altered development of Sertoli cell plays an important role in testicular digenesis syndrome [6].

There are five to six developmental time periods in PNDs) of the male rat. These stages include the neonatal (PND 0-7), infantile (PND 8-20), juvenile (PND 21-32), peri-pubertal (PND 33-55), and late pubertal (PND 56-70) periods. Male rats are sexually mature at 10 weeks of age. These periods correlate with similar developmental stages in humans [7].

At birth, the cell population of the seminiferous cords includes centrally located gonocytes which are precursors of spermatogonia and Sertoli cells distributed along basement membrane [8]. The gonocytes (primordial germ cells) at PND 3 either differentiate into type ' $A$ ' spermatogonium or degenerate by PND 9. During 1st wave of spermatogenesis, Sertoli cells divide till PND 15 and continue to differentiate and become fully functional by PND 45 with appearance of mature spermatids [9].

Development of the first wave of spermatocytes occurs at PND 15 to 18 when the testis becomes dependent on androgen produced in the postnatal period from the immature Leydig cells. At this time (PND 15 to 18), the blood-testis barrier (BTB) is formed which is morphologically identifiable double-layered rosette pattern in the seminiferous tubular epithelium and the tubular lumen first appears at (PND 18). At PND 26, round spermatids appear; and in per ipubertal period the mature sperm released into the head of the epididymis then followed by the pubertal process which continues for 2 weeks until the adult testis size and quantity of spermatozoa are reached by PND70 $[8,10]$.

Histological examination of testis in early periods of life is essential to determine the safety of new drugs for pediatric uses. The histopathologists should understand the normal development of testis to recognize the most sensitive time in development and also to determine the features of delayed puberty [11].
Therefore, the aim of the present work was to study the postnatal histological changes in the testes of rats using LM and EM.

\section{Materials and Methods}

\section{Animals}

The present study was conducted on eight healthy non-pregnant adult female albino rats weighting 150-250 gm obtained from the Scientific and Medical Research Center (SMRS) at the Faculty of Medicine, Zagazig University. The animals were housed in well ventilated wide polypropylene cages with stainless steel tops and wood shavings for bedding. Temperature was maintained at $23 \pm 2^{\circ} \mathrm{C}$. Four males were used for mating of 8 female rats at a ratio 2:1 respectively in each cage. Every morning, each female was examined for the presence of an ejaculatory plug in the vagina, an indication of mating and hence occurrence of pregnancy.

\section{Experimental protocol}

The pregnant rats were allowed to deliver naturally with nursing and their pups were counted and their sex was determined. The female pups were excluded; and males were divided into four groups, 10 pups each, according to age of the offspring at the time of scarification. The selected days were representatives for different age stages of the used animals [12-14], as follows:

- Group I: Male pups were sacrificed at PND 1(newborns).

- Group II: Male pups were sacrificed at the PND 21 (age of weaning) [12].

- Group III: Male pups were sacrificed at the PND 35 (pre pubertal age) [13].

- Group IV: Male pups were sacrificed at the PND 70 (puberty age) [14].

At the end of the experiment, all animals were anaesthetized by intra-peritoneal injection of thiopental. Their abdominal and pelvic cavities were opened; and the testes were dissected and processed for both LM and EM investigations and morphometric studies.

\section{Specimens for LM Studies}

The dissected testes were fixed in $10 \%$ formalin in water for one week. After fixation, tissues were dehydrated in ascending grades of ethanol, cleared in xylol and embedded in paraffin blocks. Sections of $5 \mu \mathrm{m}$ in thickness were cut and stained with Hematoxylin and Eosin (H\&E) stains [15]. 


\section{Journal of Embryology \& Stem Cell Research}

\section{Specimens for EM Examination}

Small pieces $(0.5 \mathrm{~mm})$ of testis from the animals of all groups were fixed immediately in $4 \%$ glutaraldehyde in $0.2 \mathrm{M}$ cacodylate buffer $(\mathrm{pH} 7.2)$ for $24 \mathrm{~h}$ at $4^{\circ} \mathrm{C}$. Specimens then post fixed in $1 \%$ OsO4 in cacodylate buffer and embedded in fresh Epon capsules. Ultrathin sections were prepared and stained with uranyle acetate and lead citrate for transmission EM examination (Jeol-JEM) at the EM unit, Mansoura University.

\section{Morphometric investigation and Statistical Analysis}

All sections were examined and photographed using Leica DM500, (German) photomicroscope. Image analysis and morphometry were performed by Image (FIJI) software. For the sections stained by H\&E, seminiferous tubule diameter, interstitial space and germinal epithelial thickness were measured in $\mu \mathrm{m}$. The collected data were computerized and statistically analyzed using Graph Pad Prism 5.01. Quantitative data were expressed as mean \pm SD (Standard deviation). Differences between mean values of experimental groups were tested with unpaired two tailed $\mathrm{t}$ test. The results were considered statistically significant when the $\mathrm{P}$ value $<0.05$.

\section{Results}

Histological examination of testes sections stained with H\&E stains showed that at PND 1 (group I) the parenchyma of the testes was formed of small rounded seminiferous cords with two cell types Sertoli cells and gonocytes. Sertoli cells had oval to elongated deeply stained nuclei; and lie along basement membrane. The gonocytes or fetal germ cells were seen as large rounded cells with dispersed chromatin and laid in the center of the tubules. The neonatal cords were widely separated by interstitial tissue which had small groups of fetal Leydig cells (Figure 1a). Examination of ultrathin sections of rat testis at PND 1 revealed that the seminiferous cords lined with germ cells. Sertoli cells rested on thin basement membrane with clear euchromatic nuclei with prominent nucleolus and its cytoplasm contain many mitochondria. Gonocytes were located at the centre of the tubule with large spherical nuclei and fine chromatin. They had one or more pale stained globular nucleoli and their cytoplasm contain many mitochondria (Figure 1b).

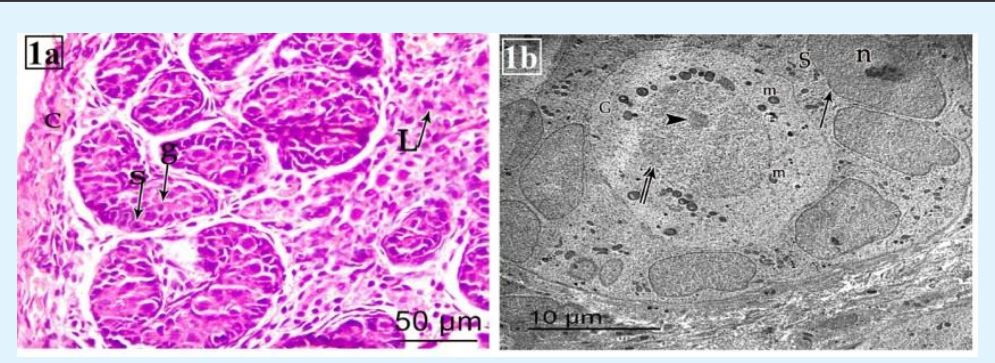

Figure 1: Sections of testis of rat aged one day (group I): a: A photomicrograph showing seminiferous cords with peripheral rim of Sertoli cells (S) and central gonocytes (G). The tubules are separated by wide interstitial tissue containing clusters of fetal leydig cells (L). The capsule (C) is formed connective tissue and spindle shaped cells with deeply stained nuclei, (H\&E X400); b: An electron micrograph showing the tubule is lined with Sertoli cells (S) resting on basement membrane and gonocyte $(G)$ centrally located. The gonocyte $(G)$ has euchromatic nucleus (double arrows) with prominent nucleolus (arrow head). Its cytoplasm contains many mitochondria (m). Sertoli cell also has euchromatic nucleus (arrow) and prominent nucleolus (n), (X3400).

At PND 21 (group II), the cell layers of the lining the tubules are increased; and formed of spermatogonia, Sertoli cells arranged into single layer along basement membrane and primary spermatocytes lying near the canter. Spermatogonia appeared as small rounded cell with rounded deeply stained nucleus. Sertoli cells had oval to elongated deeply stained nuclei. Primary spermatocytes were large rounded cells with clumped chromatin (Figure 2a). On EM investigation, spermatogonia were found to rest on a thin basement membrane with flat myoid cells. They had rounded euchromatic nuclei with marginated heterochromatin and their cytoplasm contained mitochondria. The primary spermatocytes showed large spherical nucleus with prominent nucleolus. Their cytoplasm contained mitochondria. Sertoli cells had euchromatic nuclei with prominent nucleolus with many mitochondria. It lied close to basal lamina or near the centre. It more often displaced centrally in the tubules (Figure $2 b$ ). 


\section{Journal of Embryology \& Stem Cell Research}
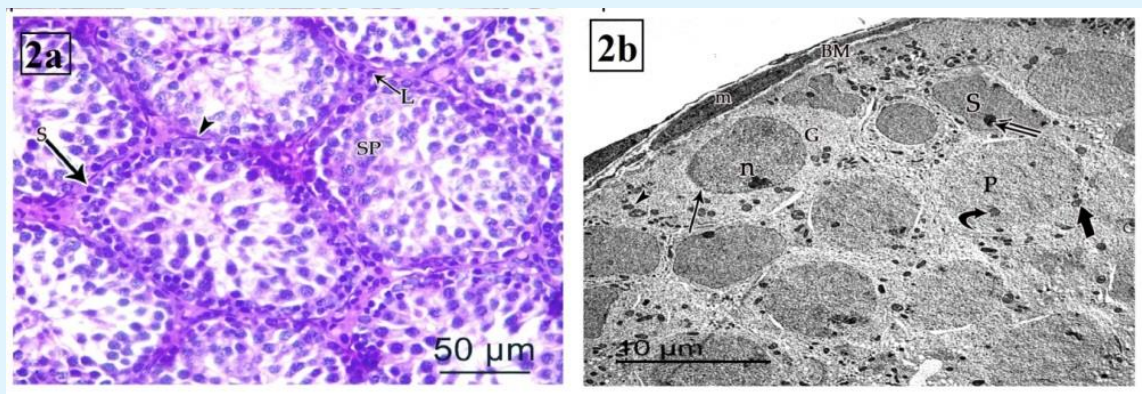

Figure 2: Sections of rats' testis at postnatal day 21 (group II): a: A photomicrograph showing seminiferous tubules surrounded by well-defined basal lamina (arrow head). The germinal epithelium is formed of Sertoli cells (arrow) and spermatogenic cells (SP). The tubules are separated by small intertubular space containing Leydig cells (L), (H\&E X400); b: An electron micrograph showing seminiferous tubule is surrounded by regular basement membrane (BM) and ensheathed with flat myoid cells $(\mathrm{m})$. Spermatogonia $(\mathrm{G})$ have spherical heterochromatic nucleus (arrow) and prominent nucleulous (n). Its cytoplasm contains many mitochondria (arrow head). Primary spermatocytes are appeared with euchromatic nucleus (P) and prominent nucleolus (curved arrow) with many mitochondria (thick arrow) in their cytoplasm. Sertoli cells have euchromatic nucleus (S) with prominent nucleolus (double arrows), (X3400).

At PND 35 (group III), the tubular diameter was increased and showed more stratification of their epithelial lining. Leydig cells were still be seen (Figure 3a). The seminiferous tubules were surrounded with well-defined basal laminae formed of flat myoid cells. The lining layers were increased; and formed of spermatogonia, Sertoli cells, primary spermatocytes and spermatids. Spermatogonia had euchromatic nucleus with peripheral heterochromain. Their cytoplasm contained mitochondria. Sertoli cell had euchromatic nucleus with prominent nucleolus; and cytoplasm contained many mitochondria. The primary spermatocytes showed large spherical euchromatic nucleus with prominent nucleolus. Their cytoplasm contained mitochondria and free ribosomes. Early spermatid with large spherical nuclei which contain chromatin clumps and peripherally located mitochondria is also observed (Figure $3 b$ ).
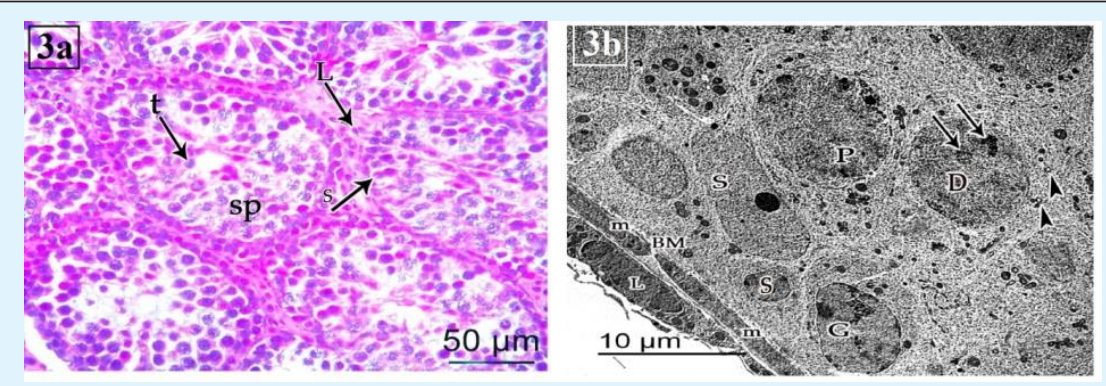

Figure 3: Sections of rats' testis at postnatal day 35 (group III): a: A photomicrograph showing well organized seminiferous tubules. The germinal epithelium is formed of Sertoli cells (S), spermatogenic cells (SP) and spermatids (t). The tubules are separated by interstitial tissue containing Leydig cells (L), (H\&E X400); b: An electron micrograph of ultrathin sections of testis of albino rat at PND 35 (group III) showing seminiferous tubule with regular basement membrane (BM) and ensheathed with flat myoid cells (m). Spermatogonia (G), Sertoli cells (S), Primary spermatocytes (P) still be seen. Early spermatid (D) with large spherical nuclei which contain chromatin clumps (arrows) and peripherally located mitochondria (arrow head) are seen. Part of intertubular space appears containing Leydig cell (L), (X3400).

At PND 70 (group IV), the testes were formed of large seminiferous tubules, closely packed together (Figure 4a).
The tubules were lined with stratified germinal epithelium and had patent lumina containing clumps of 


\section{Journal of Embryology \& Stem Cell Research}

sperms. Sperms appeared as aggregation of filamentous bundles extended into luminal side (elongated cells with deeply stained nuclei).The tubules were separated by interstitial tissue contained Leydig cells (Figure 4b). At ultrastructure level, Sertoli cells had large nuclei with finely granular chromatin and prominent nucleoli. Their cytoplasm contained mitochondria. The primary spermatocytes appeared with large rounded euchromatic nucleus with prominent nucleolus and their cytoplasm contained mitochondria and free ribosomes. Spermatids appeared with large ovoid heterochromatic nucleus. The cytoplasm contained numerous peripheral mitochondria. More mature spermatids showed acrosomal cap appeared well-fitted to one pole of the nucleus (Figure 4c).
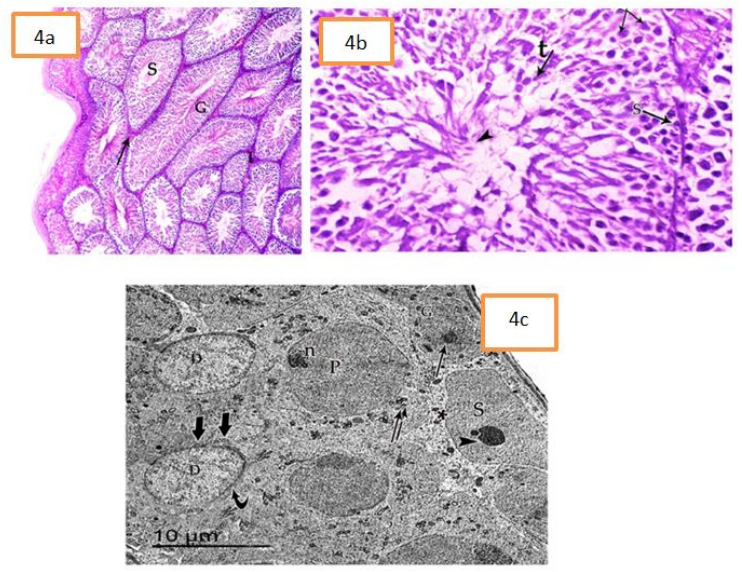

Figure 4: Sections of testis from rat at postnatal day 70 (group ID): a: A photomicrograph of showing well packed seminiferous tubules $(S)$ with well - developed lumen and are lined with stratified germinal epithelium (G). The interstitial tissue (I) contains clusters of Leydig cells (arrow), (H\&E X100); b: A photomicrograph of a section of testis at postnatal day 70 (group IV) showing that seminiferous epithelium is with different layers of spermatogenic cells (SP), Sertoli cells (S), spermatid ( $\mathrm{t}$ ) and acidophilic material of sperm bundles (arrow head), (H\&E X400); c: An electron micrograph micrograph of ultrathin section of testis of rat at PND 70 (group IV) showing seminiferous tubule is lined with Sertoli cell, spermatogonia, primary spermatocyte and spermatids. Sertoli cells have euchromatic nucleus $(\mathrm{S})$ with prominent nucleolus (arrow head). There are many mitochondria $(*)$ in the cytoplasm. The spermatogonia have euchromatic nucleus with peripheral heterochromatin (G) and prominent nucleolus (arrow). Primary spermatocyte has euchromatic nucleus (P) and prominent nucleolus (n). Its cytoplasm contains many mitochondria (double arrows). Spermatids have heterochromatic nuclei (D) and acrosomal cap (curved arrow) is fitted to one side of nucleus with peripherally arranged mitochondria (thick arrow), (X3400).

The seminiferous tubule diameter was higher in adult group than neonatal, juvenile and peri-pubertal groups (Figure 5). Regarding the interstitial space, it decreased in adult group compared to neonatal group (Figure 6). The germinal epithelium thickness was higher in adult and peri-pubertal groups. The epithelial thickness in neonatal and juvenile groups could not be measured as tubules not canalized (Table 1).

\begin{tabular}{|c|c|c|c|c|}
\hline Parameter & $\begin{array}{l}\text { Group I (PND 1) } \\
\text { Mean } \pm \text { SD }\end{array}$ & $\begin{array}{c}\text { Group II (PND 21) } \\
\text { Mean } \pm \text { SD }\end{array}$ & $\begin{array}{c}\text { Group III (PND 35) } \\
\text { Mean } \pm \text { SD }\end{array}$ & $\begin{array}{c}\text { Group IV (PND 70) } \\
\text { Mean } \pm \text { SD }\end{array}$ \\
\hline \multirow{2}{*}{$\begin{array}{c}\text { Seminiferous tubule diameter } \\
(\mu \mathrm{m})\end{array}$} & 34.97 & 47.79 & 77.86 & 126.5 \\
\hline & \pm 3.190 & \pm 4.559 & \pm 5.642 & \pm 5.081 \\
\hline \multirow{2}{*}{ Interstitial space $(\mu \mathrm{m})$} & 7.59 & 5.7 & 4.387 & 5.42 \\
\hline & \pm 2.130 & \pm 1.450 & \pm 0.640 & \pm 1.084 \\
\hline \multirow{2}{*}{$\begin{array}{l}\text { Germinal epithelium } \\
\text { thickness }(\mu \mathrm{m})\end{array}$} & \multirow{2}{*}{\multicolumn{2}{|c|}{$\begin{array}{l}\text { No data } \\
\text { The tubules were not canalized yet }\end{array}$}} & 22.04 & 39.04 \\
\hline & & & \pm 3.014 & \pm 6.038 \\
\hline
\end{tabular}

Table 1: Morphometry of studied groups. 


\section{Journal of Embryology \& Stem Cell Research}

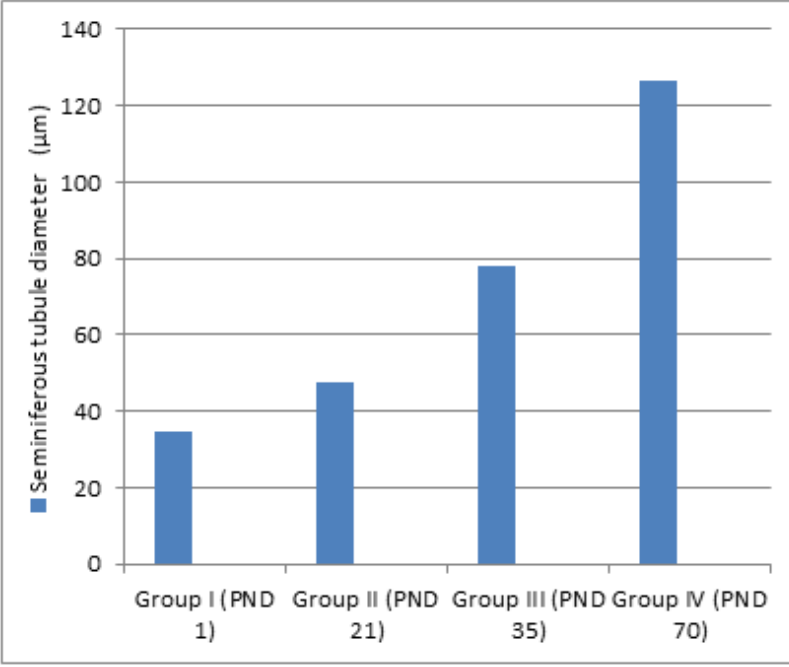

Figure 5: Columns showing the means of seminiferous tubules' diameters.

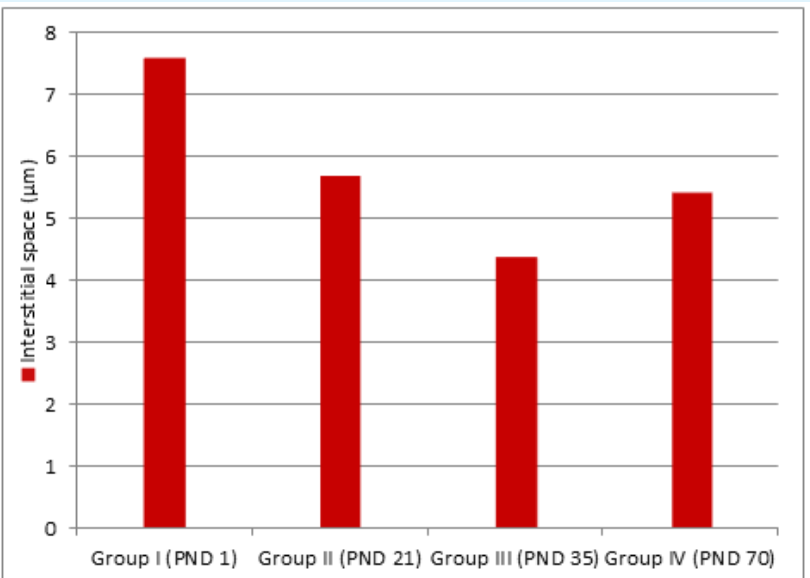

Figure 6: Columns showing the means interstitial space width.

\section{Discussion}

The rats were chosen as experimental animals in this study as their fertility is susceptible to a variety of events as in human. Moreover, it has been suggested that human fertility is more in danger as the output of human sperms is approximately four times less than other mammals [16]. Also, the rats have biological similarities to humans in addition the rodents develop diseases over a span of days or weeks instead of months or years for humans as mentioned by Aitman, et al. [17].
Kondo, et al. [18] stated that the first wave of spermatogenesis in rats occurs from the first six to seventh weeks of postnatal life. It represents the key process in sexual maturation. The prepubertal stage is much more sensitive to testicular alteration by environmental toxin. In the present study, the light microscopic examination of sections of testis in the first postnatal day (group I) revealed that testis was formed of multiple solid seminiferous cords separated by wide interstitial tissue. The cords were lined by single layer of spermatogenic cells and Sertoli cells resting on thin basement membrane. The most prominent feature in rats at PND 1 was the presence of gonocytes (spermatogonia stem cells) which were larger in size, fewer in number with pale stained cytoplasm and lied in the central portion of the cords. These results are in coincident with the studies of Berensztein, et al. [19] and Kleymenova, et al. [20] who stated that the newborn testis is formed of solid cords with two main cell types and wide intertubular space.

The solid seminiferous cords didn't have lumen and this finding is in agreement with Weber, et al. [21] and Picut, et al. [10] who mentioned that the tubular lumen starts to open on postnatal day 18. Russell, et al. [22] mentioned that the developed lumina are normally formed by the effect of tubular fluid that usually stir from the apical part of Sertoli cells and with growth of blocking intersections between Sertoli cells. The paracellular backflow was prohibited and this fluid was pushed towards the inside to canalize it.

In the present work, examination of H\&E-stained sections from rats of group II (PND 21) and III (PND 35) revealed that the tubules demonstrated stratification of their lining epithelium; more than one layer were recognized. Tubular diameter was increased and intertubular space was decreased as established by morphometric studies. The lining cells were spermatognia, primary spermatocytes and Sertoli cells; and ensheathed by a single layer of flat myoid cells. The spermatids were be demonstrated in PND 35 (group III). This is an agreement with Kim, et al. [23] who stated that the seminiferous tubules of rats at PND 42 (peripubertal period) were formed of spermatogonia, spermatocytes and spermatids and development of the lumen was observed. In the current study, examination of the testis at different ages stained with H\&E showed that the seminiferous tubules surrounded by well-defined spindle shaped cells representing the basal lamina. This is in agreement with Christl [24] who stated that the lamina propria of the testis of mouse, rat, and rabbit consists of 


\section{Journal of Embryology \& Stem Cell Research}

basal lamina fibroblasts, collagen fibers and myofibroblasts.

In the same group, examination of ultrathin sections of testis of rats of the same groups (II \& III) showed that spermatogonia were seen resting on the basement membrane with rounded nuclei and clumps of marginated heterochromatin. Their cytoplasm contained few mitochondria. The primary spermatocytes were characterized by a large spherical nucleus with few heterochromatin and their cytoplasm contained mitochondria. These results are in accordance with Xie, et al. [25] who stated that mitosis occurred in both germ cells and Sertoli cells in this age.

Moreover, the ultrathin sections of testis of the same groups (II\&III) revealed that spermatogonia had euchromatic nuclei resting on regular basement membrane. Primary spermatocytes contained many mitochondria. Sertoli cells had euochromatic nuclei with many mitochondria within the cytoplasm; and the testicular interstitium contained Leydig cells and blood capillaries. These data are in agreement with Xie, et al. [25] and Prince [26].

Examination of the Sertoli cells of prepupertal rats of group II (PND 21) and III (PND 35) showed clearly defined nuclei, occasionally located adjacent to the basal lamina but more often displaced centrally within the cords. These findings are in agreement with Allen and Cameron [27] who added that the nuclei of Sertoli cells showed one or more small nucleoli together with clumps of heterochromatin. Johnson, et al. [28] mentioned that the Sertoli cell number that established during the prepubertal period determines the final testicular size and the number of sperms produced in sexually mature animals. This is explained by França, et al. [29] who stated that Sertoli cell division stops before puberty, with the Sertoli cell population becoming stable thereafter.

Examination of H\&E-stained sections from the testes of adult group (PND 70) showed that the testicular parenchyma was formed of larger seminiferous tubules packed together compared to the prepupertal groups. Iczkowski, et al. [30] reported that the volume of the testis kept on increasing till reaching the adulthood size and was associated with an increase in the diameter of the tubules and the thickness of germinal epithelium. Although the seminiferous tubules diameters increases with increasing volume of testis, the interstitial tissue was found to be less in size than that of neonatal animals. This might be attributed to encroachment of the enlarging tubules. Gaytan, et al. [31] also added that the development of rat testis is nearly completed at 70 days of age.

The ultrastructure findings of the same group revealed that spermatogonia were laid on thin regular basement membrane. They had rounded nuclei with clumps of marginated heterochromatin. Primary spermatocytes appeared with larger sized euchromatic nuclei. They appeared with cytoplasmic continuity between each cell and its sister cell. This finding is in agreement with Cormack [32] who elucidated that there are intercellular connections between the spermatogonia and their subsequent divisions of their progeny cells.

The results of the current study revealed that Sertoli cells in adult group (IV) showed large nuclei with finely granular chromatin and prominent nucleoli. This finding is in agreement with Myers, et al. [33] who reported that heterochromatin is rarely noted within the nucleus except in association with the nucleolus.

It has been concluded that sexual differentiation and development of gonads starting early in the intra-uterine life continue after birth; and reach full sexual maturation at adult stage 'about age of two months in rats'. Continuous development of the testis after birth makes it more susceptible to hazards of environmental contaminations. Therefore, future studies are recommended to investigate such hazards that could affect the testis and fertility capability of males.

\section{Funding: None}

\section{Conflict of Interest: None}

\section{References}

1. Schill WB, Comhaire FH, Hargreave TB (2006) Andrology for the Clinician. Springer Science \& Business Media pp: 1-4.

2. Holdcraft RW, Braun RE (2004) Androgen receptor function is required in Sertoli cells for the terminal differentiation of haploid spermatids. Development 131(2): 459-467.

3. Hegazy A (2014) Clinical embryology for medical students and postgraduate doctors, Lap Lambert Academic Publishing, Berlin.

4. Carlson BM (2014) Human Embryology and Developmental Biology. $5^{\text {th }}$ (Edn.), McGraw-Hill. 


\section{Journal of Embryology \& Stem Cell Research}

5. Wilhelm D, Palmer S, Koopman P (2007) Sex determination and gonadal development in mammals. Physiological reviews 87(1): 1-28.

6. Hutchison GR, Scott HM, Walker M, McKinnell C, Ferrara D, et al. (2008) Sertoli cell development and function in an animal model of testicular dysgenesis syndrome. Biol Reproduc 78(2): 352-360.

7. Ojeda S, Skinner MK (2006) Knobil and Neill's physiology of reproduction. $4^{\text {th }}$ (Edn.), In: Puberty in the rat pp: 2061-2126.

8. Picut CA, Remick AK (2017) Impact of age on the male reproductive system from the pathologist's perspective. Toxicologic pathology 45(1): 195-205.

9. Suttie AW, Leininger JR, Bradley AE (2017) Boorman's Pathology of the Rat: Reference and Atlas, $2^{\text {nd }}(E d n$.$) .$

10. Picut CA, Ziejewski MK, Stanislaus D (2018) Comparative aspects of pre-and postnatal development of the male reproductive system. Birth defects research 110(3): 190-227.

11. Salonia A, Rastrelli G, Hackett G, Seminara SB, Huhtaniemi IT, et al. (2019) Paediatric and adultonset male hypogonadism. Nature Reviews Disease Primers 5(1): 38.

12. Hancı H, Odacı E, Kaya H, Aliyazıcıoglu Y, Turan I, et al. (2013) The effect of prenatal exposure to $900-\mathrm{MHz}$ electromagnetic field on the 21-old-day rat testicle. Reproductive Toxicology 42: 203-209.

13. Khillare B, Behari J (1998) Effect of amplitudemodulated radiofrequency radiation on reproduction pattern in rats. Electro and Magneto biology 17(1): 43-55.

14. Kesari KK, Behari J (2012) Evidence for mobile phone radiation exposure effects on reproductive pattern of male rats: role of ROS. Electromagn biol Med 31(3): 213-222.

15. Hegazy R, Hegazy A (2015) Hegazy' Simplified Method of Tissue Processing (Consuming Less Time and Chemicals). Annals of International Medical and Dental Research 1(2): 57.

16. Amann RP, Howards SS (1980) Daily spermatozoal production and epididymal spermatozoal reserves of the human male. The Journal of urology 124(2): 211215.
17. Aitman TJ, Critser JK, Cuppen E, Dominiczak A, Fernandez Suarez XM, et al. (2008) Progress and prospects in rat genetics: a community view. Nature genetics 40(5): 516-522.

18. Kondo T, Shono T, Suita S (2006) Age-specific effect of phthalate ester on testicular development in rats. J pediatr surg 41(7): 1290-1293.

19. Berensztein EB, Sciara MI, Rivarola MA, Belgorosky A (2002) Apoptosis and proliferation of human testicular somatic and germ cells during prepuberty: high rate of testicular growth in newborns mediated by decreased apoptosis. J Clin Endocrinol Metabol 87(11): 5113-5118.

20. Kleymenova E, Swanson C, Boekelheide K, Gaido KW (2005) Exposure in utero to di (n-butyl) phthalate alters the vimentin cytoskeleton of fetal rat Sertoli cells and disrupts Sertoli cell-gonocyte contact. Biology of reproduction 73(3): 482-490.

21. Weber MA, Groos S, Aumüller G, Konrad L (2002) Post-natal development of the rat testis: steroid hormone receptor distribution and extracellular matrix deposition. Andrologia 34(1): 41-54.

22. Russell LD, Bartke AJ, Goh C (1989) Postnatal development of the sertoli cell barrier, tubular lumen, and cytoskeleton of Sertoli and myoid cells in the rat, and their relationship to tubular fluid secretion and flow. Am J Anat 184: 179-189.

23. Kim YW, Kim HS, Lee JS, Kim YJ, Lee SK, et al. (2009) Effects of $60 \mathrm{~Hz} 14 \mu \mathrm{T}$ magnetic field on the apoptosis of testicular germ cell in mice. Bio electro magnetics 30(1): 66-72.

24. Christl HW (1990) The lamina propria of vertebrate seminiferous tubules: a comparative light and electron microscopic investigation. Andrologia 22(1): 85-94.

25. Xie Q, Mackay S, Ullmann SL, Gilmore DP, Payne AP (1996) Testis development in the opossum Monodelphis domestica. J Anat 189(Pt2): 393-406.

26. Prince FP (1984) Ultrastructure of immature Leydig cells in the human prepubertal testis. The Anatomical Record 209(2): 165-176.

27. Allen DC, Cameron RI (2017) Histopathology specimens: clinical, pathological and laboratory aspects. Springer. 


\section{Journal of Embryology \& Stem Cell Research}

28. Johnson L, Carter GK, Varner DD, Taylor TS, Blanchard TL, et al. (1994) The relationship of daily sperm production with number of Sertoli cells and testicular size in adult horses: role of primitive spermatogonia. Reprod 100(1): 315-321.

29. França LR, Silva Jr VA, Chiarini Garcia H, Garcia SK, Debeljuk L (2000) Cell proliferation and hormonal changes during postnatal development of the testis in the pig. Biol Reprod 63(6): 1629-1636.

30. Iczkowski KA, Sun EL, Gondos B (1991) Morphometric study of the prepubertal rabbit testis: germ cell numbers and seminiferous tubule dimensions. Am J Anat 190(3): 266-272.
31. Gaytan F, Lucena MC, Munoz E, Paniagua R (1986) Morphometric aspects of rat testis development. Journal of anatomy 145: 155-159.

32. Cormack D (2006) The endocrine system. In: Essential Histology $2^{\text {nd }}(E d n)$, Lipincott Williams\& Wilkins Philadelphia. Baltimore and Maryland.

33. Myers M, Ebling FJ, Nwagwu M, Boulton R, Wadhwa $\mathrm{K}$, et al. (2005) Atypical development of Sertoli cells and impairment of spermatogenesis in the hypogonadal (hpg) mouse. J Anat 207(6): 797-811. 